\title{
The Effects of Exercise Method and Arm Strength on 200 Meters Freestyle Swimming Achievements
}

\author{
Evan Billy Andrianto \\ Master Program in Sport Science \\ Universitas Negeri Yogyakarta \\ Yogyakarta, Indonesia \\ billyevan9@gmail.com
}

\author{
Dimyati \\ Faculty of Sport Sciences \\ Universitas Negeri Yogyakarta \\ Yogyakarta, Indonesia \\ dimy_rismi@yahoo.com
}

\begin{abstract}
Walikota Cup" in Yogyakarta, in the $200 \mathrm{~m}$ freestyle event for swimmers between the age of 10 to 11 years, there were 41 participants and Yogyakarta represented 12 male swimmers. None of the swimmers have been included in the top three in any event because $200 \mathrm{~m}$ freestyle is a middle course race that requires endurance and speed. This research was aimed at analyzing (1) the difference of interval and continuous training method on $200 \mathrm{~m}$ freestyle achievements; (2) the difference between high and low arm strength and its effect on $200 \mathrm{~m}$ freestyle achievements; and (3) The interaction of training method and arm strength and its effect on $200 \mathrm{~m}$ freestyle achievements. The research made use of an experimental method with the use of $2 \times 2$ design. The sample used in the research were 20 male swimming athletes from Yogyakarta aged 10 to 11 years. The instruments used was a $200 \mathrm{~m}$ freestyle swimming test measured with a stopwatch. The result of the research shows that (1) there is no significant effect of interval and continuous training method on $200 \mathrm{~m}$ freestyle achievements $p=0,988>0,05$; (2) there are differences between high and low arm strength in how they affect $200 \mathrm{~m}$ freestyle achievements $p=0,000<0,05$; and (3) there is no interaction between training method and arm strength on $200 \mathrm{~m}$ freestyle achievements $p=0,332>0,05$.
\end{abstract}

Keywords-interval training, continuous training, strength arm, 200m of freestyle swimming achievement.

\section{INTRODUCTION}

Despite being an aquatic sport, swimming can also be also a tool in getting some pleasures and achievements. Freestyle, one of swimming styles, is known as the fastest and the most efficient swimming style which is suitable for beginners, since it is natural and very easy to be taught and learned [1]. It has faster swimming stroke compared to other swimming styles such as butterfly, backstroke, and breaststroke [2]. 200 meters of swimming is equal to four times of 50 meters of swimming.

The National Championship Mayor Cup of 2017 was held in a swimming pool at the Faculty of Sport Science of State University of Yogyakarta. There were 12 male swimmers as a representatives of Yogyakarta performing in the group IV (1011 years old) of 200 meters freestyle. Among the representatives of Yogyakarta, none won as a result of inadequate endurance and swimming speed. The fastest time in this group was 2 minutes 21 seconds 79 milliseconds.

Swimmers must have excellent endurance and muscle strength since this kind of sport strongly depends on those factors [3]. Performance of swimmers is not only reliant on the swimming ability but also the strategy employed in using endurance. Freestyle itself is a combination of the movements of hands and feet and $90 \%$ of the propulsive force of this swimming style come from the upper extremities (arm strength, shoulder rotation, and arm rotation). This upper movements give more influences to the swimming force than feet movements [4]. The pattern of arm rotation and strength during the freestyle exercise should not be changed. Some researches show that the substantial improvements can be made through the last round in the swimming sprint and the middle of second lap of swimming in 200 meters [5].

The process of attaining some swimming achievements can be optimally developed due to the sense of competition possessed by human beings. Every kind of sports require a good physical quality to achieve the honor and this physically quality must be developed and improved along with the needs of each sport. Good swimmers are those who develop great skills, have little resistance during the competition, and show long and powerful strokes that increase their speed [6]. The 200-meter freestyle is classified under medium distance category. It demands high speed and endurance over the duration of time and requires energy that comes from the supply of glycoses' system [7].

Moreover, some other important factors in swimming include the starting as well as techniques employed in rotating [8]. The suitable technique selected and the position of the body - the eyes, shoulders, hips, and ankles - on the surface of the water break the water efficiently. As a swimmer moves through the water, his/her head will face the bottom of the pond, while his/her abdominal area (shoulder to hip) and lower area (hip to ankle) will roll on the sideways. This position, developed through various training models as instructed by the trainer, helps freestyle swimmer to swim better.

The main purpose of the exercise is to bring about the improvement of skills, abilities, and achievements of an athlete. An effective exercise can be achieved by the application of some trainings based on the age, quality and capabilty of the athlete [10]. Swimming exercises should always be consistently taken. Another benefit of swimming is to grow the components of the body especially for the children. The children who are in the multilateral age (elementary school age) are more suitable for aerobic development, flexibility, and some trainings to expand their coordination, balance or speed [11]. Briefly, the main objectives of engaging in some exercises include (a) improvement of basic physical quality generally and comprehensively, (b) development and enhancement of specific physical potentials, (c) addition and refinement of 
techniques, (d) development and refinement of strategies, techniques and play patterns, and (e) improvement of the quality and psychic competence of the athletes for competition [12].

This research used an exercise method with interval exercise of $70-90 \%$ and continuous exercise of $55-70 \%$. Interval training is an exercise that involves using the oxygen that is already existing in the muscle. It contains of speed training which might be inform of a rhythm of exercise-breakexercise with the period of break longer than the exercise [12]. Continuous training provides a training with short time of break or in the other words the athlete keeps exercising [12]. A training has the possibility of showing some anaerobic and aerobic improvements which was carried out through the application of 18 times of meeting, one pretest, sixteen treatments with a one-week frequency of three meetings, and one post-test to get the final result.

\section{METHOD}

\section{A. Experimental method}

The research used pre-test, mid-test, and post-test for selected swimming athletes of several private swimming clubs in Sleman-Yogyakarta.

\section{B. Time and Place of Research}

The research was conducted at the swimming pool of Depok Sport Center and Faculty of Sport Science, State University of Yogyakarta from May to June 2018. The exercise was held 16 times at a frequency of 3 times per week. Duration of exercise was about 90 minutes for each meeting and was held between 15.30-17.00 WIB.

\section{Population and Sample}

The population used was the male swimming athletes of several private swimming clubs in Sleman-Yogyakarta with the age range of 10 to 11 years old. The samples were determined by random sampling.

TABLE I. RESEARCH DESIGN FRAMEWORK

\begin{tabular}{|l|c|c|}
\hline Exercise method (A) & $\begin{array}{c}\text { Interval } \\
\text { Training } \\
\text { (A1) }\end{array}$ & $\begin{array}{c}\text { Continuous } \\
\text { Training } \\
\text { (A2) }\end{array}$ \\
\hline Strongth of the arms (B) & A1B1 & A2B1 \\
\hline Weak (B2) & A1B2 & A2B2 \\
\hline
\end{tabular}

Information:

A1B1: A group of athletes with strong arm strength treated with interval training method.

A2B1: A group of athletes with strong arm strength treated with continuous training method.

A1B2: A group of athletes with weak arm strength treated with interval training method.

A2B2: A group of athletes with weak arm strength treated with continuous training method.

\section{The Techniques and Instruments for Data Collection}

The technique used for data collection was through the provision of pre-test and post-test before and after the given treatment respectively. On the other hand, this study used pull up as the instrument for the measurement of arm strength.

\section{E. Technique of Data Analysis}

The technique employed in data analysis a was SPSS 20 for windows applications. Hypothesis examination was done through the use of analysis of variance (ANOVA) with the significance level of 0.05 . Before the application of ANOVA on the data, prerequisite tests consisted of normality test of the data using Kolmogrov Smirnov and homogeneity test using Levene Statistic with a probability value of $(p>0,05)$ were firstly done.

\section{RESULTS AND DISCUSSION}

\section{A. Description of the Data}

This research was organized at two pools: Depok Sport Center and the Faculty of Sport Science, State University of Yogyakarta. The number of samples taken was 20 athletes which were further divided into four groups and labelled: strong arm strength groups trained with interval training (A1B1) and with continous training method (A2B1), weak arm strength trained by interval training method (A1B2) and with continous training method (A2B2). The results are displayed in the Table below.

TABLE II. STATISTIC RESULTS OF PRETEST AND POSTTEST OF 200M FREESTYLE SWIMMING.

\begin{tabular}{|c|c|c|c|c|}
\hline Treatments & Attributive & Statistics & Pretest & Posttest \\
\hline \multirow{6}{*}{$\begin{array}{l}\text { Interval } \\
\text { Training } \\
\quad(A 1)\end{array}$} & \multirow{3}{*}{$\begin{array}{c}\text { Strong arm } \\
\text { strength (B1) }\end{array}$} & Sum & 882.67 & 873.64 \\
\hline & & Average & 176.534 & 174.728 \\
\hline & & SD & 4.50447 & 4.86782 \\
\hline & \multirow{3}{*}{$\begin{array}{c}\text { Weak arm } \\
\text { strength (B2) }\end{array}$} & Sum & 927.78 & 922.84 \\
\hline & & Average & 185.556 & 184.568 \\
\hline & & SD & 2.69201 & 2.99831 \\
\hline \multirow{6}{*}{$\begin{array}{c}\text { Continuous } \\
\text { Training } \\
\text { (A2) }\end{array}$} & \multirow{3}{*}{$\begin{array}{c}\text { Strong arm } \\
\text { strength (B1) }\end{array}$} & Sum & 869.99 & 865.01 \\
\hline & & Average & 173.998 & 173.002 \\
\hline & & SD & 4.37200 & 4.46729 \\
\hline & \multirow{3}{*}{$\begin{array}{c}\text { Weak arm } \\
\text { strength (B2) }\end{array}$} & Sum & 934.34 & 931.73 \\
\hline & & Average & 186.868 & 186.346 \\
\hline & & SD & 2.74045 & 2.96595 \\
\hline
\end{tabular}

\section{B. Test Prerequisite}

Here, the normality test was done with the use of Kolmogrov Smirnov method. This test was carried out for each group with the use of SPSS 20 program with significance level of $5 \%$ or 0,05 . The following results show its data. 
TABLE III. TEST OF NORMALITY

\begin{tabular}{|c|c|c|c|}
\hline Data & $p$ & Significance & Information \\
\hline Pretest A1B1 & 0,816 & \multirow{8}{*}{0,05} & Normal \\
\hline Posttest A1B1 & 0,515 & & Normal \\
\hline Pretest A2B1 & 0,934 & & Normal \\
\hline Posttest A2B1 & 1.000 & & Normal \\
\hline Pretest A1B2 & 0,552 & & Normal \\
\hline Posttest A1B2 & 0,953 & & Normal \\
\hline Pretest A2B2 & 0,944 & & Normal \\
\hline Posttest A2B2 & 0,925 & & Normal \\
\hline
\end{tabular}

The homogeneity test was done using Levene Statistic method with a significance level of $5 \%$ or 0.05 . The result is showed as follows:

TABLE IV. TEST OF HOMOGENEITY

\begin{tabular}{|l|c|c|c|c|c|}
\hline \multicolumn{7}{|c|}{ Test of Homogeneity of Variances } \\
\hline & Levene Statistic & f1 & df2 & Sig. & Information \\
\hline Pretest & 2.347 & 3 & 24 & .098 & Homogen \\
\hline Posttest & 1.698 & 3 & 24 & .194 & Homogen \\
\hline
\end{tabular}

\section{Test of Hypothesis}

Differences in the influence of interval training and continuous training methods on the $200 \mathrm{~m}$ freestyle achievement were tested.

The sig value of $0.988 \geq 0.05$ indicates the acceptance of $\mathrm{H}_{0}$ and the rejection of $\mathrm{H}_{\mathrm{a}}$. In other words, this shows there is no significant difference between the influence of interval training and continuous training method on the $200 \mathrm{~m}$ freestyle achievement. Thus, the first hypothesis states that both training methods show the same effect on the influence of arm strength over the enhancement of $200 \mathrm{~m}$ freestyle achievement.

According to the sig value of $0.000 \leq 0.05$, it indicates the rejection of $\mathrm{H}_{0}$ and the acceptance of $\mathrm{H}_{\mathrm{b}}$, this means that there is a significant difference between the influence of highly and weakly motivated students over the $200 \mathrm{~m}$ freestyle achievement. Thus, the second hypothesis states that a strong arm strength gives better positive impact on $200 \mathrm{~m}$ freestyle achievement.

The interaction between the exercise methods and the arm strength over the increase of $200 \mathrm{~m}$ freestyle achievement.

The sig value of $0.332 \geq 0.05$ points out the acceptance of $\mathrm{H}_{0}$ and the rejection of $\mathrm{H}_{\mathrm{c}}$. Based on this result, it can be concluded that the training methods and the arm strength do not have any significant effect on $200 \mathrm{~m}$ freestyle achievement. Thus, the third hypothesis states that there is no significant difference between the interaction of both exercise methods and the arm strength over $200 \mathrm{~m}$ of freestyle swimming.

\section{Discussion}

There are no influential differences between the interval and continuous training methods over the achievement of $200 \mathrm{~m}$ of freestyle swimming.

Interval training shows a rapid increase of oxidative muscle capacity and sports performance [13]. Interval training has a longer time of break than the exercise. It is expected that the participants will do a lot of different movements to improve their freestyle swimming skill by this training method.

On the other hand, continuous training is an aerobic exercise that does not have any break time [14]. The interval training has a stratified effect on the endurance.

Continuous training plays an important role in the improvement of VO2Max. This kind of training gives some influences over the breath-hold duration and the pulse so that it brings a positive change in the athlete's physiological parameters. While the interval training method plays with the speed, it is expected that the participants consume more oxygen so that it can improve the achievement of the $200 \mathrm{~m}$ of freestyle swimming.

Based on the explanations above, both the interval or continuous exercise method have advantages and disadvantages. At the same time, they both have positive impacts in developing freestyle swimming skill. Therefore, those training methods have the same effect over the achievement of $200 \mathrm{~m}$ of freestyle swimming.

The arm strength has influence on the achievement of $200 \mathrm{~m}$ of freestyle swimming.

Endurance exercise definitely causes fatigue. During such circumstances, the athlete is required to be able to perform until a certain time. Because the endurance exercise is tedious and exhaustive, high will and strong strength are essential.

Based on some of the above explanations, it can be concluded that a person with high arm strength gives a better effect than a swimmer with low arm strength on the achievement of $200 \mathrm{~m}$ of freestyle swimming.

There is no interaction between the training methods and the arm strength over the achievement of the $200 \mathrm{~m}$ freestyle swimming.

Exercise methods that were used in this research include the interval and continuous training. On the other hand, strength has a very important role to play in all activities that are related to achieving the desired goal. It is one of the factors that must be considered by parents, teachers, trainers, and scientists so that in the future there will be optimization of the athletes. However, based on the results of this study there is no interaction between the exercise methods and arm strength on the achievement of $200 \mathrm{~m}$ freestyle swimming. The exercise method has its own role in improving the swimming performance and same thing is applicable to the arm strength.

\section{CONCLUSION}

Some parameters have been studied over the influences of the achievement of $200 \mathrm{~m}$ freestyle swimming by athletes. The results show that there is not any significant difference between the effects of interval and continuous training methods.

The two training methods possess the same influence. On the other hand, some difference effects have been shown in the case of the arm strength. The strong arm strength gives positive results, and vice versa. It was discovered that there is no correlation between training methods and arm strength in influencing achievement of $200 \mathrm{~m}$ freestyle swimming. 


\section{REFERENCES}

[1] S. Meredith, Mengajar anak berenang. Usbome publishing. 2006.

[2] J. M. Monu, Journal sport specific training for a competitive freestyle sprint swimmer. 2013. Volume 35.

[3] J. A. Arroyo. \& J. M. Gonzalez, "Effect of specific strength training on sprint swim performance," Imperial journal of interdisciplinary research. 2017. Volume 3.

[4] S. A. Heinlein, and A. J. Cosgarea. Biomechanical considerations in the competitive swimmer's, 2010.shoulder.Journal.doi: 10.1177/1941738110377611.

[5] E. Y. Robertson, Analysis of lap times in international swimming competitions. 2009, Volume 27.Journal.doi.org/10.1080/02640410802641400

[6] T. O. Bompa, \& M. Carrera, Conditioning young athletes. Canada: Human Kinetics. 2015.

[7] Y. Hongchuna, The $r \& d$ of a swimmer training speed navigator based on the $13^{\text {th }}$ fina world championships. 2014. Journal.doi: 10.1016/j.proeng.2014.06.142.
[8] J. M. Monu, Journal sport specific training for a competitive freestyle sprint swimmer. 2013. Volume 35.

[9] T. O. Bompa, Theory and methodologi of training. Toronto: Kendal/Hunt Publishing Company. 2015.

[10] Suharjana, Kebugaran jasmani, Yogyakarta, Jogja Global Media, 2013.

[11] Sukadiyanto, Pengantar teori dan metodologi melatih fisik. Yogyakarta. UNY. 2010.

[12] M. Sloth, dkk. "Effect of sprint training on vo2max and aerobic exercise performance: A systematic review and meta analysis," 2013. Journal.doi: 10.1111/sms. 12092.

[13]B. R. McKay, D. H. Paterson, \& J. H. Kowalchuk, "Effect of short-term high intensity interval training vs continue training on $\mathrm{O} 2$ uptake kinetics, muscle deoxygenation, and exercise performance," J Appl Physiol, 2009, Vol 107: 128-138.

[14]Babu, S \& Kumar, P. "Effect of continuous fartlek and interval training on speed abd coordination among male soccer players," Journal of Physical Education and Sports. Management. 2014. Vol 1 no 1. 33-41. 